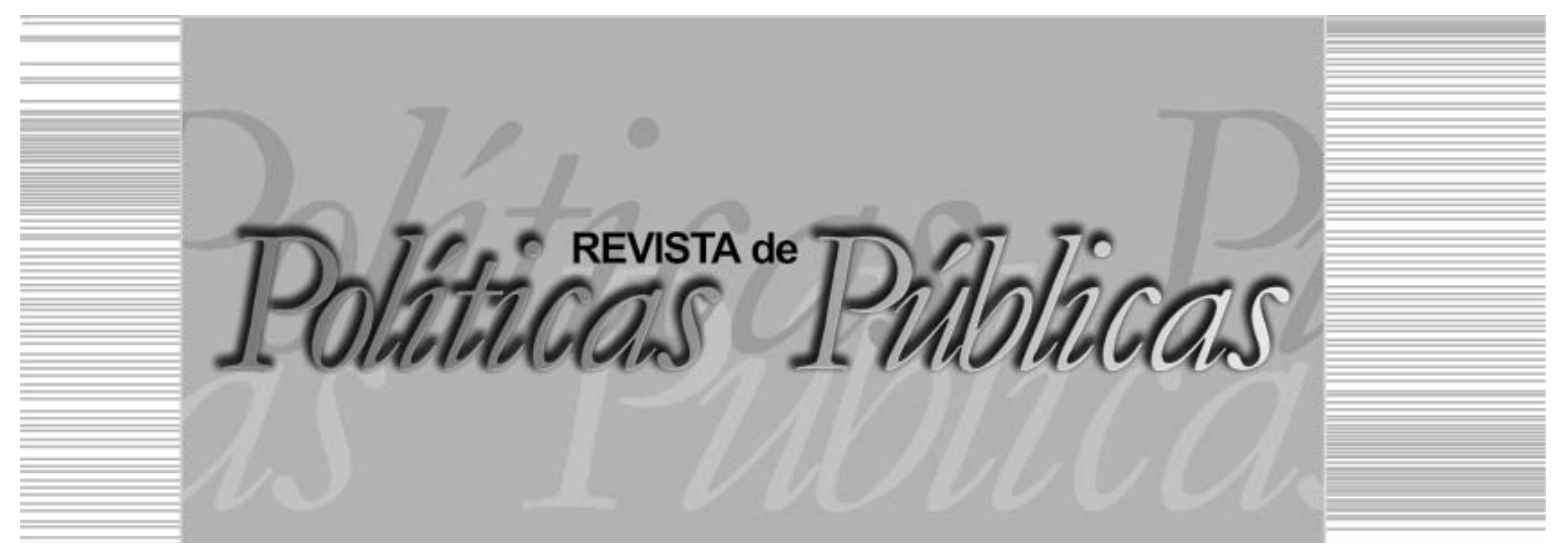

\title{
PESCADORES ARTESANAIS E A EXPANSÃO PORTUÁRIA NA PRAIA DO BOQUEIRÃO, ILHA DE SÃO LUÍS-MA
}

\author{
Itatiane Ribeiro ${ }^{1}$ \\ Universidade Estadual do Maranhão (UEMA) \\ Antonio Carlos Leal de Castro ${ }^{2}$ \\ Universidade Federal do Maranhão (UFMA)
}

\section{Resumo}

Descrição de focos de conflito socioambientais decorrentes da polarização entre a atividade portuária e a pesca artesanal na praia do Boqueirão. $\mathrm{O}$ estudo ocorreu no período de janeiro a abril/2014, utilizando como métodos a observação participante e entrevistas com aplicação de questionários. Verificou intensos conflitos socioambientais na região tanto entre a Vale e os pescadores, quanto entre pescadores nascidos no Boqueirão e pescadores oportunistas. Dos problemas ambientais percebidos, destacam-se o lixo, a construção do Píer IV e o resíduo de minério de ferro lançado no mar. A evolução do uso e ocupação do solo demonstrou que a área estudada vem apresentando modificações de caráter antrópico que tem provocado a degradação ambiental do ecossistema, tais como aumento do banco de areia e deposição de minério, que pode afetar diretamente a comunidade pesqueira local.

Palavras-chave: Pescador artesanal, expansão portuária e conflitos socioambientais.

\footnotetext{
Bióloga. Mestra em Sustentabilidade de Ecossistemas. Professora de Biologia do Programa Darcy Ribeiro da Universidade Estadual do Maranhão (UEMA). E-mail: tatympbio@, hotmail.com

2 Engenheiro Agrônomo. Doutor em Ciências da Engenharia Ambiental. Professor Adjunto do Programa de Pós-Graduação em Sustentabilidade de Ecossistemas da Universidade Federal do Maranhão (UFMA). E-mail: alec@ufma.br|Universidade Federal do Maranhão - UFMA | Cidade Universitária Dom Delgado |Av. dos Portugueses, n. 1966, Bacanga, São Luís/MA | CEP: 65085-580
} 


\title{
ARTISAN FISHERMEN AND PORT EXPANSION ON BOQUEIRÃO BEACH, ISLAND OF SÃO LUIS-MA
}

\begin{abstract}
This study aimed to evaluate the main focuses of social and environmental conflicts arising from the polarization between port activities and the practice of artisanal fishing on Boqueirão beach. The study took place from january to april, 2014 with monthly sampling. We used participant observation and interviews with application of semi-structured questionnaires. There were intense social and environmental conflicts in the region, both between Vale and fishermen, and between fishermen born in Boqueirão and "opportunistic" fishermen. Among the perceived environmental problems are waste (41\%), construction of the pier IV (22\%) and ore residue thrown into the sea (15\%). The evolution of the use and occupation of the soil showed that the study area has shown, over the years, anthropic modifications that have caused environmental degradation of the ecosystem, such as increased sand banks and ore deposition, which can affect directly the local fish community.

Key words: Artisanal fisher, port expansion and Social and environmental conflicts.
\end{abstract}

\section{INTRODUÇÃO}

A zona costeira do Maranhão possui uma extensão de 640 $\mathrm{Km}$, na qual está inserida uma plataforma larga, com águas costeiras rasas e sob influência de descarga de numerosos rios, formando uma série de baías e estuários ligados por canais naturais através de manguezais. (STRIDE, 1992).

No litoral sob influência do golfão maranhense, encontram-se as mais extensas áreas de estuários do país, fato decorrente das expressivas amplitudes de marés e, consequentemente, esse complexo estuarino representa um potencial que deve ser considerado no desenvolvimentoeconômico do estado. (CASTRO, 2001).

Esses atributos ambientais transformam o litoral em uma área muito atrativa e desejada, tanto em nível urbano, quanto industrial, especialmente pelo potencial para abrigar terminais portuários e outros empreendimentos, tornando-se áreas de intensos conflitos de interesses e profundos impactos ambientais que colocam em risco os atuais usos e ocupações.

Em que pese às particularidades de cada região, pode-seafirmar que a maior parte da zona costeira brasileira enfrenta problemas complexos de degradação ambiental, na maioria das vezes articula- 


\section{PESCADORES ARTESANAIS E A EXPANSÃO PORTUARIA \\ NA PRAIA DO BOQUEIRÃO, ILHA DE SÃO LUÍS-MA}

dos com ocupações inadequadas e sérios problemas socioeconômicos da população local. (BRASIL, 2008).

A questão do uso e ocupação do solo está associada aos crescentes impactos observados na zona costeira, a qual vem sendo progressivamente ocupada por grandes projetos de interesse e desenvolvimento regional, impondo a necessidade de se definir protocolos que contemplem o monitoramento e o manejo mais racional das situações de conflito. Consideradas estratégicas, as margens do estuário sempre foram alvo do interesse econômico para a contínua expansão portuária, tanto da parte de agentes do mercado como pela ação articulada entre as três esferas executivas do poder público. (ROMANI, 2010).

A partir da década de 1970, iniciou-se em São Luís a atividade portuária, onde os impactos gerados vêm causando alterações na dinâmica marinha das áreas próximas ao complexo portuário, afetando diretamente a atividade pesqueira das populações inseridas nessas regiões.

Entre os principais impactos destacam-se a redução na disponibilidade de habitats das comunidades aquáticas, a poluição por efluentes industriais, o assoreamento e atividades de dragagens. (CARVALHO-NETA; TORRES; ABREU-SILVA, 2012). Como resultados deste processo surgem dilemas e conflitos acerca do manejo dos habitats naturais, principalmente diante da diversidade de interesses e agentes frequentemente conflituosos.

No Brasil, assim como em boa parte dos países menos industrializados, as decisões de localização dos projetos de transformação sócio-ecológica, associadas à implantação de infraestruturas requeridas pelos processos de acumulação/desenvolvimento, priorizam áreas ocupadas pelos grupos de baixa renda, comunidades tradicionais, indígenas e extrativistas, atores sociais que compartilham áreas de uso comum. (ACSELRAD, 2004).

Na zona oeste da ilha de São Luís, conformado pela baía de São Marcos, estão localizadas as áreas que apresentam melhores condições para implantação de novos terminais portuários, atingindo profundidades naturais variáveis entre 17 a 23 metros na baixa mar. Este setor abriga o funcionamento do Complexo Portuário de São Luís. (AMARAL, 2006). 
Nesse panorama, o presente estudo busca descrever os principais focos de conflitos socioambientais decorrentes da polarização entre a atividade portuária e a prática da pesca artesanal na praia do Boqueirão, a fim de oferecer subsídios que permitam integrar os interesses dos diferentes grupos sociais na definição de um futuro sustentável para a região.

\section{MATERIAL E MÉTODOS}

\section{1 Área de estudo}

A ilha de São Luís está localizada entre as coordenadas de 02 $24^{\prime} 09^{\prime \prime}$ S- $02^{\circ} 46^{\prime} 13^{\prime \prime}$ S e $44^{\circ} 01^{\prime} 20^{\prime \prime} \mathrm{W}-4^{\circ} 29^{\prime} 47^{\prime \prime} \mathrm{W}$, encontrando como limites a oeste, a baía de São Marcos; a leste a baía de São José; ao sul o Estreito dos Mosquitos e ao norte, o Oceano Atlântico. A divisão geopolítica atual determina a composição territorial da ilha de São Luís em quatro municípios: São Luís, São José de Ribamar, Paço do Lumiar e Raposa. (ALMEIDA et al., 2011).

A praia do Boqueirão (Figura 1) encontra-se inserida na zona oeste da ilha de São Luís e vem sofrendo intensas transformações, devido à ampliação do Terminal Portuário da Ponta da Madeira (TPPM) que ensejou a construção de mais um cais de atracação de navios (Píer IV). Essa área foi desapropriada pela VALE em meados da década de 1970 para a implantação do TPPM. Após a remoção das famílias, supressão da vegetação e restrição dos locais de pescas, conflitos socioambientais entre a empresa e a comunidade de pescadores artesanais foram intensificados nessa região.

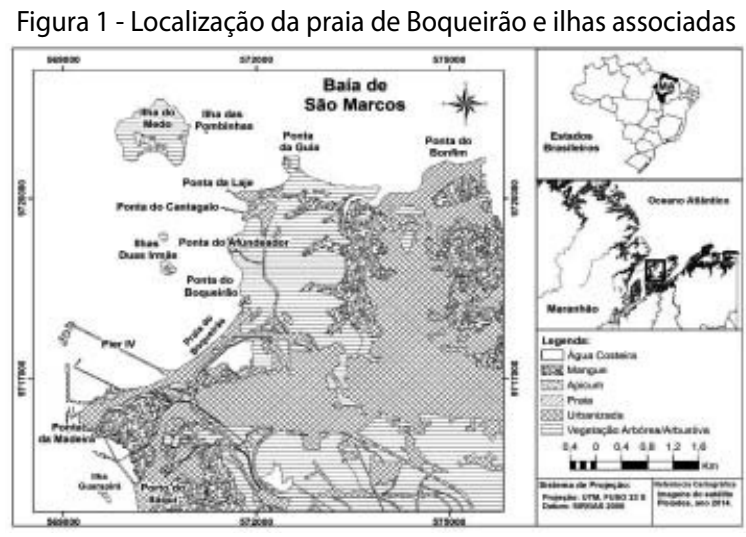

Fonte: Imagens de Satélite Pleiades (2014). 


\section{PESCADORES ARTESANAIS E A EXPANSÃO PORTUARIA \\ NA PRAIA DO BOQUEIRÃO, ILHA DE SÃO LUÍS-MA}

A delimitação da praia compreende uma faixa de terra que se inicia no TPPM, nas imediações do Píer I, e segue em direção as áreas do fundiador, onde se encontra estabelecida a comunidade de pescadores do Boqueirão. Este trecho contínuo de praia recebe diversas denominações como, Canta Galo, Ponta da Lage, Guia, Carnaubal e Bonfim. Fazem parte ainda deste cenário as ilhas Duas Irmãs, Pombinha e Grande, conhecida também como Ilha do Medo (devido aos intensos naufrágios ocorridos nessa região).

\subsection{Coleta e Análise de dados}

Precedente à coleta de dados primários foram realizadas visitas de reconhecimento junto à comunidade litorânea que permitiu um resgate histórico e a obtenção de informações pertinentes ao conflito vivido. Para tal utilizou-se a técnica História de Vida pela qual foi possível captar o processo de memória e reflexão crítica do indivíduo sobre suas vivências tidas em condições sociais altamente específicas. (VIERTLER, 2002).

Os participantes foram esclarecidos sobre os objetivos e métodos propostos para obtenção dos dados, sendo assegurado a eles o direito de acesso aos mesmos.

As amostragens mensais ocorreram no período de junho/2013 a abril/2014. Como métodos de coleta de dados utilizaram-se a Observação Participante e entrevistas, a fim de compreender situações e acontecimentos relevantes para a pesquisa. (ATKINSON; HAMMERSLEY, 1994). Em seguida, aplicaram-se questionários semiestruturados que abordaram a questão ambiental e o perfil socioeconômico da população de pescadores da praia do Boqueirão.

Foram entrevistados 25 pescadores, universo amostral validado pelo Relatório do Programa de Apoio à Pesca Artesanal na Praia do Boqueirão (VALE, 2009) e ratificado pelos pescadores mais antigos da região, representando $100 \%$ da comunidade local, que têm a pesca como fonte de renda exclusiva ou secundária.

A técnica de listagem livre (Free Listing) foi utilizada para analisar a percepção do pescador sobre os peixes capturados em grande quantidade e que atualmente inexistem ou diminuíram, bem como, os peixes que não eram pescados e agora estão presentes nas capturas. (MIRANDA; AMOROZO, 2003). 
Informalmente conversou-se com pescadores menos experientes. Assim, pode-se dizer que a informação também foi reunida em partículas, já que cada pescador encontrado foi considerado uma fonte de conhecimento. (EVANS-PRITCHARD, 2007).

Para a elaboração dos mapas de uso e ocupação do solo utilizaram-se imagens dos anos de 1988 e 2012, as quais foram georreferenciadas, e posteriormente, montadas em mosaico no programa SPRING 5.2.3. (CAMARA, 1996). O processamento e análise dos dados foram realizados nos programas JMP 3.2.6. (SAS INSTITUTE, 1995) e Microsoft Office Excel (versão 2010).

\subsection{Resultados e Discussão}

\subsubsection{Resgate histórico da Comunidade do Boqueirão}

A praia do Boqueirão foi habitada há mais de três décadas por uma comunidade de pescadores que exercia a pesca de forma predominantemente artesanal, tendo ao longo de sua extensão mais de 50 famílias. As principais atividades desenvolvidas, além da pesca, consistiam na olaria (fabricação de tijolos e potes), coleta de coco babaçu e fabricação de farinha.

A pesca era praticada de forma individual e coletiva, respeitando-se os laços de parentesco, já que é comum que os pescadores realizem a atividade em parceria com membros de sua família. A prática era desenvolvida para subsistência, sendo, eventualmente, o excedente comercializado na própria comunidade por meio de atravessadores, em bairros próximos ou de forma eventual no Centro Histórico de São Luis, visto que o acesso a esse ponto era realizado apenas por via marítima.

A privação do contato com outras culturas acabou contribuindo para preservar e perpetuar sua cultura originária. Desse modo, a existência das famílias do Boqueirão ocorreu em função dos conhecimentos que produziam acerca das características ambientais de seu meio circundante.

No entanto, em meados de 1970, essa realidade começou a ser alterada. A região de Itaqui Bacanga passou a ser percebida como potencial econômico na medida em que sua localização oferecia a possibilidade de construção de portos e infraestrutura aquaviária. A 


\section{PESCADORES ARTESANAIS E A EXPANSÃO PORTUARIA \\ NA PRAIA DO BOQUEIRÃO, ILHA DE SÃO LUÍS-MA}

partir deste marco temporal iniciaram-se intensos conflitos socioambientais na região. (SANT’ANA-JUNIOR, 2009).

2.3.2 Conflitos socioambientais na comunidade de pescadores da praia do Boqueirão

- VALE versus Pescadores Artesanais

Os conflitos geralmente podem ser considerados disputas originadas por interesses adjacentes entre dois ou mais atores, com valores, ideologias e modos de vida, os quais entram em choque em virtude de diferentes lógicas de gestão dos bens coletivos de uso comum. (CASTILHO, 2012).

Acselrad (2004) considera que os conflitos ambientais, como os que envolvem grupos sociais com modos diferenciados de apropriação, uso e significação do território, se originam quando pelo menos um dos grupos tem ameaçada a continuidade de suas formas de apropriação, por impactos indesejáveis transmitidos pelo solo, água, ar ou sistemas vivos em decorrência do exercício das práticas de outros grupos.

Desse modo, os conflitos socioambientais podem ser entendidos como disputas entre grupos sociais derivadas dos distintos tipos de relações por eles mantidas com o seu meio natural, podendo emergir em torno do controle sobre determinados recursos e/ou envolvendo os valores e modos de vida em torno do uso do ambiente. (LITTLE, 2004).

No Maranhão, os conflitos socioambientais se configuram desde o início da década de 80 e continuam a surgir em diferentes escalas e dimensões. Desde então, a atuação de grandes empreendimentos na Ilha do Maranhão tem ocasionado inúmeros conflitos, que giram, sobretudo, em torno de processos agrários, urbanos e industriais. (CARVALHO, 2009; SANT'ANA-JUNIOR, 2009).

Mesmo que os impactos sejam discursivamente amenizados, por exemplo, através da incorporação de noções como sustentabilidade, responsabilidade socioambiental ou medidas compensatórias, os conflitos decorrentes desses avanços continuam a se aprofundar.

Na praia do Boqueirão, o primeiro ponto de conflito iniciou-se quando os pescadores começaram a ter a sua realidade modificada, resultado da ampliação da atividade do TPPM. Após meses de 
lutas e negociações entre a população do Boqueirão e a Amazônia Mineração/AS-AMSA, pela permanência dos moradores no seu local de origem, o progresso venceu e a população foi indenizada e transferida para uma localidade chamada Morro Pelado, atualmente Alto da Esperança, residencial construído para abrigar os moradores deslocados.

Segundo Diegues (2001), as populações tradicionais, em geral, vivem em relativo isolamento, possuem pouco poder político, são analfabetas e não costumam ter títulos de propriedade da terra, por isso são facilmente desapropriadas sem que sejam realmente compensadas pela expropriação do espaço que habitavam há gerações.

Após a remoção das famílias, um subgrupo da população retornou com seus ranchos de pesca, a fim de garantir sua sobrevivência por meio do uso dos recursos naturais e preservação de sua cultura local, marcada pelos conhecimentos tradicionais transmitidos entre as gerações.

Porém, diante da extrema importância do TPPM para a economia do Estado e prevendo um crescimento na demanda de minério no mercado exterior, a estrutura física do Terminal teve sua expansão projetada sob a forma do Píer IV, obra externa (offshore), o qual faz parte de um conjunto de obras iniciadas em 2010, e que já é considerada a maior obra de infraestrutura portuária da América Latina.

De acordo com Cunha (2006), a gestão das zonas costeiras exige uma profunda compreensão dos fenômenos físicos, químicos e biológicos, a fim de proteger as comunidades que nela habitam.

O Estudo de Impacto Ambiental (EIA) da Vale definiu a praia do Boqueirão, que inclui o trecho de mar utilizado pelos pescadores artesanais, como Área de Influência Direta (AID) da construção do PIER IV, que corresponde à área geográfica, que potencialmente poderá sofrer impactos ambientais significativos gerados pela implantação e operação do empreendimento e que deve ser contemplada por programas e ações para prevenir, eliminar ou minimizar impactos ambientais significativos ou adversos. (VALE, 2008).

Diante disso, desde 2008 a Vale vem realizando diversas ações junto à comunidade pesqueira. Conforme relatório:

Ciente da sua responsabilidade social perante os impactos causados com a implantação do Píer IV do Terminal Portuário de Ponta 


\title{
PESCADORES ARTESANAIS E A EXPANSÃO PORTUÁRIA NA PRAIA DO BOQUEIRÃO, ILHA DE SÃO LUÍS-MA
}

\begin{abstract}
da Madeira, em São Luís, a Vale está realizando o Programa de Desenvolvimento Socioeconômico da Comunidade de Pescadores Artesanais da Praia do Boqueirão. Por isso, por meio da Fundação Vale, propusemos a construção participativa de um programa de apoio à pesca artesanal na praia do Boqueirão. Foram realizadas reuniões com pescadores e lideranças comunitárias e também articulações com o sindicato, o Serviço Brasileiro de Apoio às Micro e Pequenas Empresas (SEBRAE), o Serviço Nacional de Aprendizagem Comercial (SENAC) e o Estaleiro Escola, assim como visita às instalações do porto da Vale. (VALE, 2010, p.78).
\end{abstract}

A primeira etapa do programa, desenvolvida em 2009, incluiu a realização de uma pesquisa que classificou os pescadores em três grupos, de acordo com sua atividade de pesca para melhor definir o atendimento. Foram inscritos 51 pescadores no programa, junto com suas famílias, os quais participaram de qualificações e como forma de compensação passaram a receber mensalmente uma bolsa-auxílio vinculada à participação em cursos oferecidos pela Vale, entre eles Saúde do Pescado Artesanal, Trabalhador no Beneficiamento de Pescado, e Carpintaria.

No entanto, segundo os entrevistados, os cursos aconteciamem locais distantes da comunidade e em períodos de pescarias mais intensas ou em dias inapropriados que os privavam dos convívios familiares (sexta a domingo). Logo, a inviabilidade dessa ação ficava evidenciada na fala de um dos entrevistados: "[...] nós já temos a idade avançada, não temos mais o que aprender, e se a gente aprender qual empresa vai nos contratar?" (Informação verbal) ${ }^{1}$.

Segundo eles, além da incoerência, a Vale também teria decretado a eliminação automática do trabalhador, caso o mesmo não cumprisse a carga horária. "Os cursos, simplesmente, não têm sentido algum, se nós não estivermos pescando. Como vamos, de uma hora para outra, abandonar a vida de pescadores para sermos carpinteiros ou pedreiros, se desde criança a única coisa que faço é pescar?" (Informação verbal)2.

O programa inclui ainda a distribuição de materiais de pesca artesanal, kit de segurança e apoio para obtenção de documentos pessoais. Até 2012, tempo previsto para a duração dessa ação. Porém depois de novas negociações a mesma passou a ter vigência de mais três anos, estendendo-se até 2015.

Nota-se que, apesar de organizar e planejar programas e ações dirigidos aos pescadores do Boqueirão, a VALE ainda enfrenta situ- 
ações conflitantes que caracterizam um verdadeiro impasse. Isso ficou evidente na fase da implantação do programa, quando uma parte dos pescadores apresentou resistência à negociação proposta pelo empreendedor devido ao pagamento da bolsa-auxílio, em três grupos, onde o primeiro receberia o valor de $\mathrm{R} \$ 1.500,00$; o segundo, $\mathrm{R} \$ 1.000,00$ e o terceiro $\mathrm{R} \$ 724,00$.

A argumentação se sustenta no fato de que essa divisão ocorreu de forma arbitrária, visto que os valores deveriam ser definidos com base na expectativa de vida, e ainda que o benefício pudesse ser transferível ${ }^{3}$.

Observou-se que as obras de instalação do Píer IV vêm causando danos ambientais devido à retirada da vegetação local e alterações permanentes do meio ambiente, afetando o cotidiano de toda a comunidade, que há anos pratica a pesca na região. Embora tenha sido manifestada a insatisfação dos pescadores diante das medidas de compensação, o poder de decisão dos pescadores foi desconsiderado no processo.

Em 2009, um grupo de 70 pescadores (inclusos e não inclusos no Programa da Vale) organizou-se e, juntamente com o apoio da Colônia de Pescadores Z-10 fundaram a Associação da Comunidade de Pescadores Artesanais da Praia do Boqueirão. Estes articularam uma ação judicial contra a empresa de consultoria Diagonal, responsável pela construção do diagnóstico socioeconômico na área de influência da Estrada de Ferro Carajás. (PANTOJA, 2010). Após negociações os pescadores foram indenizados.

Sobre a manifestação dos pescadores da praia do Boqueirão, a Vale esclareceu a situação por meio da seguinte nota:

Os pescadores não serão impedidos de exercer suas atividades na praia do Boqueirão durante implantação e operação do Píer IV, no Terminal Portuário de Ponta da Madeira. A restrição refere-se apenas à faixa de segurança, conforme orienta a Capitania dos Portos. Em outubro de 2008, a Vale iniciou um processo de livre negociação com os pescadores da praia do Boqueirão, onde foram realizadas até o momento mais de 50 reuniões com a equipe de diálogo social e especialistas em pesca, com o objetivo de levantar o perfil socioeconômico destes profissionais e de suas famílias, além de conhecer sua atividade pesqueira. ${ }^{4}$

Porém os pescadores relataram que a construção do Píer IV levou à privação de acesso às suas áreas de pesca, impossibilitando 


\section{PESCADORES ARTESANAIS E A EXPANSÃO PORTUARIA \\ NA PRAIA DO BOQUEIRÃO, ILHA DE SÃO LUÍS-MA}

o uso pela população local. Nesse sentido, a sobreposição da zona de exclusão portuária gerada pela proximidade ou inserção do terminal portuário aos pesqueiros utilizados pelos pescadores, implica diretamente na supressão da atividade da pesca no local, uma vez que o acesso a esses territórios passa a ser completamente proibido para a navegação, com exceção das embarcações autorizadas.

- "Filhos do Boqueirão" versus Pescadores "de fora"

Outro ponto de conflito evidente ocorre entre os pescadores que nasceram ou foram criados na praia do Boqueirão, autodenominados Filhos do Boqueirão e os pescadores de fora, que são aqueles que vêm de outras localidades e que eventualmente exercem a atividade de pesca na praia. Os entrevistados confirmam que alguns destes estão inclusos no programa de bolsas da Vale e "[...] nunca molharam o pé na água e aproveitam dos bens que são de direito dos pescadores do Boqueirão." (Informação verbal).

Infere-se que tal interesse venha sendo motivado pela especulação de uma nova indenização pela Vale, o que tem levado à construção de novos ranchos de pesca na comunidade, fato que havia alterado as relações de convivência no grupo do Boqueirão.

Atualmente existem mais de 27 ranchos, dos quais só 17 são oficialmente cadastrados pela Vale, sendo a maioria utilizada para guardar instrumentos de pesca, visto que os pescadores têm residências fixas em outras localidades (Anjo da Guarda, Alto da Esperança, Fumacê, Vila Embratel, Vila Isabel, e demais bairros na área Itaqui-Bacanga).

\subsubsection{Percepção de impactos ambientais e mudanças na pesca}

A maioria dos entrevistados tem a percepção de que a abundância de peixe diminuiu e que o mesmo vem sofrendo uma forte alteração no tamanho $(80 \%)$ nos últimos anos, o que tem comprometido a produção, conforme relatado por um dos entrevistados: "Se antes eu passava uma hora na praia e pegava $10 \mathrm{Kg}$ de tainha, agora eu passo 10 horas e não pego $1 \mathrm{Kg}$." (Informação verbal) ${ }^{6}$.

Quando questionados sobre o local de captura, $84 \%$ dos entrevistados disseram que o mesmo vem sendo comprometido. Tais evidências levaram $61 \%$ dos entrevistados a declararem que nada mais pode ser feito para reverter a situação atual da pesca na região, visto que para $26 \%$ a única alternativa seria a retirada do 
Tais inquietações são evidenciadas na fala de um dos entrevistados "A pesca do Boqueirão agora vai mesmo acabar. Não tem mais jeito, a tendência é ficar pior e acabar com tudo, pois não pode tirar o Píer." (Informação verbal) 7 . Esse pensamento tem levado 9\% dos pescadores a desejarem a bolsa-auxílio para todos os residentes na área do Boqueirão.

Durante a fase de expansão foram estabelecidas zonas de exclusão permanentes, uma vez que as restrições consistem no impedimento da realização de atividades de pesca num raio de $300 \mathrm{~m}$. Essa demarcação espacial abrange a área onde existe a maior abundância e diversidade de peixes. Segundo $72 \%$ dos pescadores o acesso ao recurso é muito controlado, o que tem prejudicado a captura das espécies.

Quando questionados sobre a existência dos peixes que existiam em grande quantidade e que atualmente vem diminuindo em abundância, observou-se que a tainha (Mugil sp) foi a mais citada (28\%). Esses dados coincidem com os levantamentos ictiofaunísticos realizados na Ilha de São Luís, onde as três espécies dominantes foram: Genyatremus luteus (24\%), seguida por Mugil curema $(11,6 \%)$ e Ariusherz bergii $(11,2 \%)$. (MARTINS-JURAS; JURAS; MENEZES, 1987; SILVA-JUNIOR et al., 2013).

Na década de 90, estudos sobre os aspectos ecológicos da ictiofauna estuarina da Ilha de São Luís, também registraram estas três espécies como mais abundantes: G. luteus $(17,36 \%)$, A. herzbergii $(13,25 \%)$, M. curema $(9,7 \%)$, estas foram capturadas com redes de emalhar e espinhel nos estuários Cururuca, Paciência, Estreito dos Coqueiros, Tibiri, baías de São Marcos e São José. O autor atribui esse padrão de dominância numérica ao tipo de ambiente estuarino onde essas espécies são capturadas. (CASTRO, 1997).

Quando questionados sobre os problemas ambientais que mais interferem na pesca, os mais citados foram: o lixo (41\%) e o resíduo de minério lançado no mar (15\%). Durante as amostragens em campo foram identificados 2 pontos de derramamento de esgoto e 6 bueiros, responsáveis pelo lançamento de resíduos de minério no mar (Figura 2). 


\section{PESCADORES ARTESANAIS E A EXPANSÃO PORTUARIA NA PRAIA DO BOQUEIRÃO, ILHA DE SÃO LUÍS-MA}

Figura 2 - Localização das fontes pontuais de poluição da praia do Boqueirão

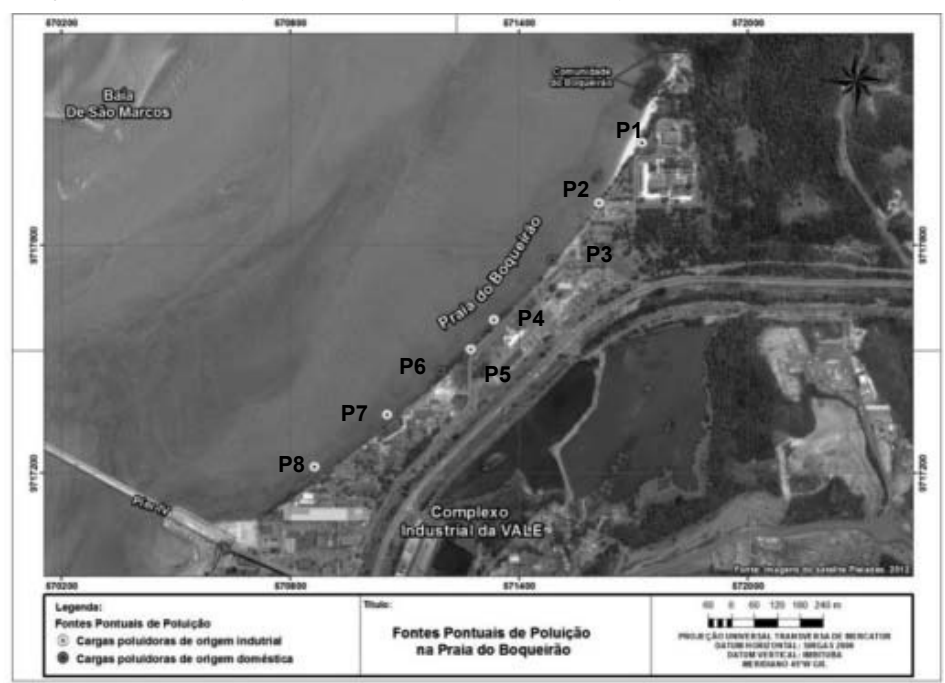

Fonte: Imagens de Satélite Pleiades (2014).

Para os entrevistados, o contaminante lançado no mar é o minério de Ferro, por conta da cor característica desse minério (vermelho). Para validar a informação dos pescadores no dia 06/05/2014, foram realizadas duas coletas de água diretamente no local de descarga de origem industrial (P1 e P8). As amostras foram analisadas no Laboratório de Química de Solos da Universidade Estadual do Maranhão (UEMA), tendo como limite de detecção do aparelho para o Ferro 0,1 mg/L. (BAUMGARTEN; ROCHA; NIENCHESKI, 1996).

De acordo com os resultados, o ponto localizado junto à comunidade (P1) apresentou valores de Ferro dentro do limite permitido. Já o ponto próximo ao Píer IV (P8) apresentou valores de Ferro $(2,8 \mathrm{mg} / \mathrm{L})$ muito acima do valor máximo permitido pela Resolução CONAMA 357/2005 (0,3 mg/L Fe) para corpos de água onde haja pesca ou cultivo de organismos para fins de consumo intensivo. (COMISSÃO NACIONAL DO MEIO AMBIENTE, 2005).

Dados apresentados no Zoneamento Costeiro do Estado do Maranhão revelam que na última década tem ocorrido contaminação química causada por esgotos, escoamento de nutrientes e descargas de indústrias, principalmente para as áreas de influência do com- 
plexo portuário de São Luís, o que pode ser uma ameaça crescente na saúde dos organismos aquáticos (UNIVERSIDADE FEDERAL DO MARANHÂO; UNIVERSIDADE ESTADUAL DO MARANHÃO, 2003).

Presume-se que esses metais possam estar sendo introduzidos no ambiente estuarino, não só por fontes naturais, como também pelas atividades portuárias na exportação e processamento dos minérios de ferro, manganês e bauxita.

Essas informações ratificam estudos realizados pelo Programa de Monitoramento da biota aquática e avifauna, qualidade de águas costeiras e sedimento marinho - Píer IV. Registros de concentrações de metais analisados na água mostraram que o alumínio, manganês, cobre e ferro apresentaram valores acima do máximo permitido. (VALE; UNIVERSIDADE FEDERAL DO MARANHÃO, 2012).

Estudos realizados por Carvalho-Neta, Torres e Abreu-Silva (2012) evidenciaram respostas biológicas alteradas para a espécie estuarina-residente (S. herzbergii) no complexo portuário, em cujas águas e sedimentos foram detectados vários poluentes acima dos níveis permitidos pela legislação ambiental brasileira

Em consonância a estes dados, exemplares de bagres estuarinos (Sciadesherz bergii e Bagre bagre), confirmaram várias alterações histológicas, sugerindo que os bagres dessa região estão com a saúde comprometida, provavelmente em função da exposição desses organismos aos poluentes da região portuária. (SOUSA; ALMEIDA; CARVALHO-NETA, 2013).

Diante desse quadro, o cenário de potencial contaminação do pescado na praia do Boqueirão é bastante preocupante, dada a imensa importância social e econômica da pesca para a população local.

\subsubsection{Evolução da área de uso e ocupação do solo}

Após os cálculos das diferentes classes de uso e ocupação do solo para a praia do Boqueirão, obteve-se a quantificação da área $\left(\mathrm{m}^{2}\right)$ das diferentes unidades de paisagem para os anos de $1988 \mathrm{e}$ 2012 .

A análise das unidades de paisagem demonstra que a área estudada vem apresentando, ao longo dos anos, modificações de caráter antrópico que têm provocado a degradação ambiental do 


\section{PESCADORES ARTESANAIS E A EXPANSÃO PORTUÁRIA \\ NA PRAIA DO BOQUEIRÃO, ILHA DE SÃO LUÍS-MA}

ecossistema, tais como aumento do banco de areia e a deposição de minério, que podem comprometer a navegabilidade e afetar diretamente a comunidade de peixes local (Tabela 1). Segundo relato dos entrevistados, esse impacto ambiental tem ocasionado, também, o surgimento de algumas dermatoses nas pessoas que habitam a área costeira do Boqueirão.

Tabela 1 - Superfície das unidades de paisagem $\left(\mathrm{m}^{2}\right)$ da praia do Boqueirão nos anos de 1988 e 2012

\begin{tabular}{l|c|c}
\hline \multicolumn{1}{c|}{ Uso e cobertura do solo } & Área $\left(\mathrm{m}^{2}\right)-1988$ & Área $\left(\mathrm{m}^{2}\right)-2012$ \\
\hline Água Costeira & 5762,73 & 4343,08 \\
\hline Banco de Areia & 880,96 & 1101,12 \\
\hline Área de Praia de Areia & 111,01 & 9,93 \\
\hline Área de Praia de Rochosa & 11,72 & 6,87 \\
\hline Lavado & 22,10 & 1047,59 \\
\hline Manguezal & 571,67 & 574,80 \\
\hline Apicum & 2,56 & 1,73 \\
\hline Lago & 5,28 & 178,57 \\
\hline Vegetação Alta & 1487,10 & 1055,83 \\
\hline Vegetação Média & 45,82 & 223,14 \\
\hline Vegetação Baixa & 839,30 & 424,98 \\
\hline Solo Exposto & 231,86 & 149,87 \\
\hline Área com ocupação humana & 23,25 & 2,15 \\
\hline Complexo Industrial da VALE & 464,99 & 1297,14 \\
\hline Área Urbano-industrial & 48,92 & 73,24 \\
\hline Comunidade do Boqueirão & 0,14 & 4,96 \\
\hline Banco de Deposição de Minério & 0,00 & 10509,41 \\
\hline & & \\
\hline
\end{tabular}

Fonte: Dados da pesquisa (2014).

Ainda diante desse cenário, $50 \%$ dos pescadores, que dizem ter o seu melhor local de pesca próximo ao Píer IV, afirmam que atualmente "[...] onde era areia e dava muito peixe, agora é lama." (Informação verbal) ${ }^{8}$. O que pode ser observado pelo aumento do 
Lavado $\left(1.047,59 \mathrm{~m}^{2}\right)$, área de praia marcada pela presença de lama (configurando um substrato inconsolidado), no ano de 2012.

Por meio dos mapas de uso e cobertura do solo dos anos de 1988 (Figura 3) e 2012 (Figura 4) foi possível identificar espacialmente as áreas de conflito, como aquelas com uso urbano-industriais consolidadas.

Figura 3 - Mapa de uso e ocupação do solo do ano de 1988 da praia do Boqueirão

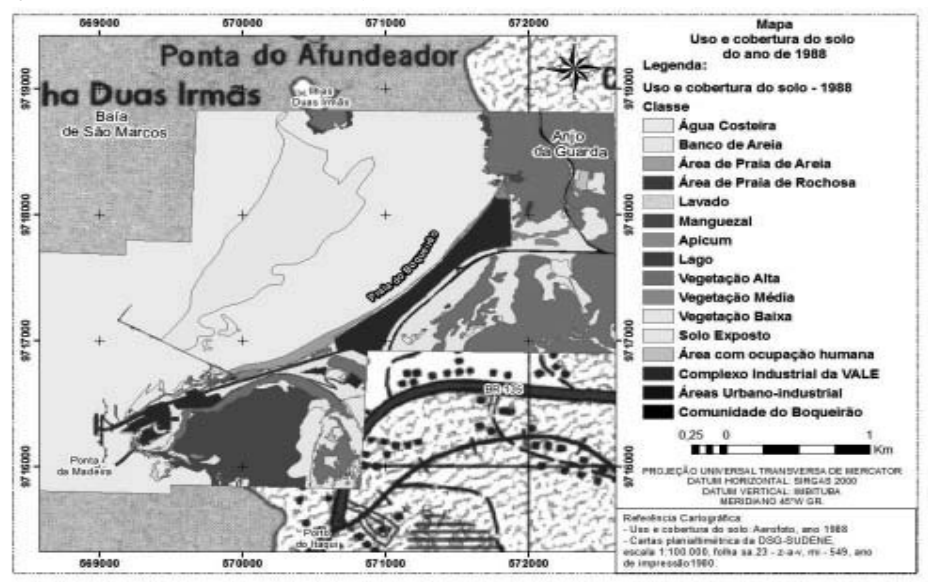

Fonte: Cartas planialtimétrica (DGS-SUDENE). Aerofoto (1988).

Figura 4 - Mapa de uso e ocupação do solo do ano de 2012 da praia do Boqueirão

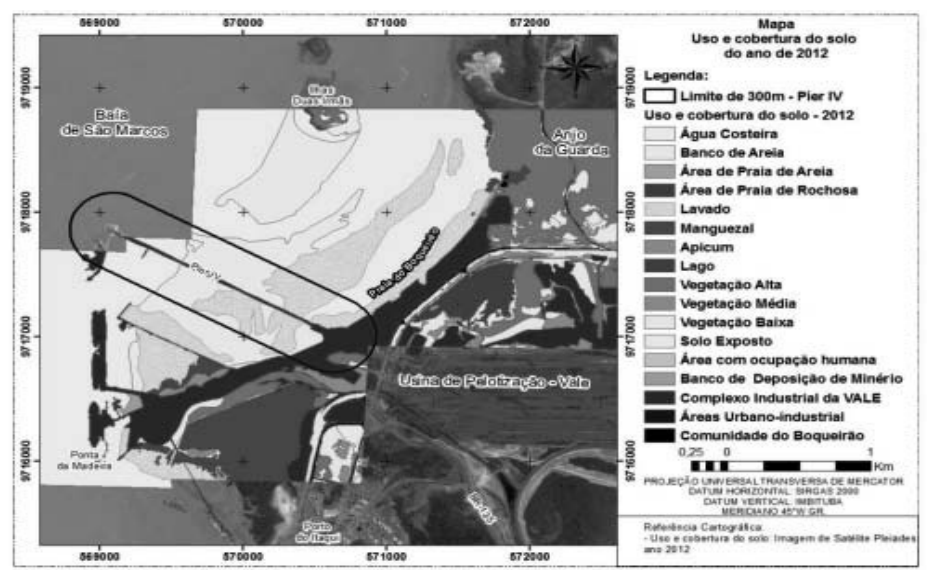

Fonte: Imagem de Satélite Pleiades (2012). 


\section{PESCADORES ARTESANAIS E A EXPANSÃO PORTUARIA \\ NA PRAIA DO BOQUEIRÃO, ILHA DE SÃO LUÍS-MA}

Analisando cenário proposto para o ano de 2012, observou-se ainda que os manguezais presentes nas localidades próximas à comunidade vêm passando por um crescente processo de alteração, confirmado pela sua colonização em ambientes antigamente inóspitos a esse ecossistema. Tal fato deve-se ao aumento dos bancos de areia cobertos por lama que criam ambientes favoráveis para a colonização por mangues.

Apesar dessa potencial colonização em um novo sítio ser benéfica ambientalmente, pode assumir futuramente um aspecto negativo, visto que o manguezal contribuiria ainda mais para a redução das velocidades das correntes de maré, e aceleraria o processo de sedimentação e assoreamento na área de pesca utilizada pela comunidade local.

Verificou-se que a transformação física do espaço na praia do Boqueirão é concreta, a quantidade de resíduos sólidos é abundante, a presença de diversos personagens alheios à pesca é nítida.

Em razão disso, os conflitos socioambientais na comunidade tendem a se agravar. Porém existe uma preocupação crescente por parte dos pescadores, os quais se mostraram receptivos à discussão de soluções, o que é positivo para futuras experiências de manejo.

\subsubsection{Acesso dos pescadores artesanais às Políticas Públicas}

A luta pelos direitos sociais se expressa na ação de movimentos sociais, representativos da sociedade civil e se concretiza na efetivação das políticas públicas. Pereira $(2008$, p. 94$)$ pondera duas interpretações a esse respeito: a primeira aponta "[...] o Estado como o produtor exclusivo de política pública [...]", e a segunda mostra "[...] a relação dialeticamente contraditória entre Estado e sociedade como o fermento da constituição e processamento dessa política."

No entanto, a política pública por ser mediada pelo Estado e pela sociedade, apresenta conflitos de interesses, o que fragiliza sua implementação. Por outro lado, convém ressaltar que as políticas públicas não são estáticas e que se modificam no tempo e no espaço em que estão inseridas.

Compreende-se que a configuração de uma política pública, cuja perspectiva de território é dispositivo de ações e intervenções, não pode se restringir a uma lógica de mera delimitação de espaços ou política administrativa para os territórios, mas deve ser baseada 
no reconhecimento das capacidades coletivas dos territórios enquanto espaços de vida e vivência com características políticas, econômicas e culturais.

Sobre a existência de projetos que visem à recuperação da área de pesca, $84 \%$ disseram que nada foi proposto e $16 \%$ relataram a existência de uma proposta para a construção de tanques para a criação de peixes ou na própria praia ou em outra localidade, o que segundo os pescadores é uma proposta inviável, por conta do deslocamento e da falta de prática com peixes de água doce. Observou-se que tais medidas vêm causando o descontentamento dos pescadores e intensificado os conflitos ambientais nessa região.

Destaca-se, assim, a luta dos pescadores artesanais para a consolidação de direitos e de cidadania, os quais por questões adversas, não têm acesso suficiente às políticas sociais públicas, principalmente aos serviços básicos como saneamento, energia, saúde, educação, assistência e direitos sociais e trabalhistas, realidade vivenciada pelos pescadores da comunidade do Boqueirão.

As observações realizadas no decorrer da pesquisa confirmam as reclamações dos pescadores sobre a inoperância da Colônia Z-10, que está deixando de realizar reuniões e/ou assembleias contínuas, o que acaba dificultando e fragilizando o processo de organização e de reivindicação dos direitos sociais, bem como das políticas públicas direcionadas à comunidade.

\section{CONCLUSÃO}

O estudo realizado permitiu conhecer o espaço da pesca artesanal, bem como seus respectivos sujeitos sociais. Observou-se que a atividade portuária promoveu profundas mudanças tanto no meio ambiente quanto na vida dos pescadores artesanais, devido à sobreposição de seus locais de pesca com as áreas de instalação do Píer IV, e que esse processo continua a impactar grupos sociais que reagem, na busca de manter seus modos de vida.

O conflito entre os pescadores e a Vale, além de ser um conflito ambiental, é também espacial, na medida em que os agentes envolvidos possuem diferentes cosmologias que se chocaram nesse encontro de trajetórias e de histórias.

Com vistas a um diagnóstico mais preciso sobre o potencial de contaminação por resíduos de minério lançados no mar e que 


\section{PESCADORES ARTESANAIS E A EXPANSÃO PORTUARIA \\ NA PRAIA DO BOQUEIRÃO, ILHA DE SÃO LUÍS-MA}

afetam diretamente a comunidade pesqueira, recomenda-se estudos mais detalhados na área, que incluam análises de outras matrizes que apresentam relevância do ponto de vista ambiental e toxicológico, tais como: sedimento, vegetação e peixes.

Entende-se que, apesar das atividades portuárias serem reconhecidamente responsáveis por inúmeros conflitos socioambientais, principalmente ao serem indutoras de intensas transformações territoriais e por seus impactos ambientais de diversas naturezas, esta possui grande importância econômica. A justificativa da ampliação de infraestruturas portuárias como necessidade estratégica para o desenvolvimento nacional é o argumento adotado pelo poder público.

Acredita-se que a discussão deve ir além do espaço institucional, pois as questões ambientais são de suma relevância, uma vez que os pescadores artesanais dependem diretamente de condições ambientais satisfatórias para sua subsistência.

\section{REFERÊNCIAS}

ACSELRAD, H. As práticas espaciais e o campo dos conflitos ambientais. In: ACSELRAD, H. (Org.). Conflitos ambientais no Brasil. Rio de Janeiro: Relume Dumará: Fundação Heinrich Böll, 2004. p 13-35.

ALMEIDA, Z. S. et al. Síntese do conhecimento sobre ictiofauna da costa maranhense, Brasil. In: NUNES, J. L. S; PIORSKI, N. M. (Orgs.). Peixes marinhos e estuarinos do Maranhão. São Luís: Café e Lápis; FAPEMA, 2011. p. 148-174.

AMARAL, R.F. Caracterização hidrossedimentológica do canal de acesso do Complexo Portuário do Maranhão. 2006. 139 f. Tese (Doutorado em Engenharia Hidraúlica e Sanitária) - Departamento de Engenharia Hidráulica e Sanitária, Escola Politécnica da Universidade de São Paulo, São Paulo, 2006.

ATKINSON, P.; HAMMERSLEY, M. (1994). Ethnography and participan to bservation. In: The SAGE handbook of qualitative research. Londres: University of Illinois, 1994. p. 248-261.

BAUMGARTEN, M. da G. Z.; ROCHA, J. M. de B.; NIENCHESKI, L. F. H. Manual de análises em oceanografia química. Rio Grande: Ed. Furg, 1996. 
BRASIL. Ministério do Meio Ambiente. Secretaria de Mudanças Climáticas e Qualidade Ambiental. Macrodiagnóstico da zona costeira e marinha do Brasil. Brasília, DF, 2008.

CAMARA, G. et al. Spring: integrating remote sensing and GIS by object-oriented data modelling. Computers and Graphics, [S. 1.], v. 20, n. 3, p. 395-403, may./jun. 1996.

CARVALHO, F. C. de. Ordenamento territorial e impactos socioambientais nodistrito industrial de São Luís - MA. In: SANT'ANA JR., H. A. et al. (Orgs.). Ecos dos conflitos socioambientais: a RESEX de Tauá-Mirim. São Luís: EDUFMA, 2009. p.41-60.

CARVALHO-NETA, R. N. F.; TORRES J. R., A. R.; ABREU-SILVA, A. L. Biomarkers in Catfish Sciades herzbergii (Teleostei: Ariidae) from Polluted and Non-polluted Areas (São Marcos' Bay, Northeastern Brazil). Apply Biochemical and Biotecnology, [S. 1.], v.166, p.1-12, 2012.

CASTILHO, A.G. Enfoque sociológico dos conflitos socioambientais e o movimento por justiça social. Caos - Revista Eletrônica de Ciências Sociais, João Pessoa, v. 21, p. 44-58, 2012.

CASTRO, A. C. L. de. Características ecológicas da ictiofauna da Ilha de São Luís - MA. Boletim do Laboratório de Hidrobiologia, São Luís, v. 10, p. 1-18, 1997.

. Diversidade da assembleia de peixes em igarapés do estuário do Rio Paciência (MA-Brasil). Atlântica, Rio Grande, v. 23, p. 39-46, 2001.

COMISSÃO NACIONAL DO MEIO AMBIENTE. Resolução CONAMA 357 - Dispõe sobre a classificação dos corpos d'água e diretrizes ambientais para o seu enquadramento, bem como estabelece as condições e padrões de lançamento de efluentes, e dá outras providências. Diário Oficial da União, Brasília, DF, 53, seção 1, 5863, 2005.

CUNHA, I. Fronteiras da gestão: os conflitos ambientais das atividades portuárias. RAP, Rio de Janeiro v. 40, n. 6, p. 1019-1040, 2006.

DIEGUES, A. C. S. O mito moderno da natureza intocada. 3. ed. São Paulo: Hucitec. 2001. 


\section{PESCADORES ARTESANAIS E A EXPANSÃO PORTUARIA \\ NA PRAIA DO BOQUEIRÃO, ILHA DE SÃO LUÍS-MA}

EVANS-PRITCHARD, E. E. Os Nuer: uma descrição do modo de subsistência e das instituições políticas de um povo nilota. 2. ed. São Paulo: Ed. Perspectiva, 2007.

LITTLE, P. E. A Etnografia dos Conflitos Socioambientais: bases metodológicas e empíricas. In: ENCONTRO DA ANPPAS, 2., 2004, Idaiatuba, SP. Papers.... Idaiatuba, 2004. p.1-9. Disponível em: $<$ http:// www.anppas.org.br/encontro_anual/encontro2/GT/GT17/gt17_little. pdf $>$. Acesso: 28 jul. de 2013.

MARTINS-JURAS, I. A. G.; JURAS, A. A.; MENEZES, N. A. Relação preliminar dos peixes da ilha de São Luís, Maranhão, Brasil. Revista Brasileira de Zoologia, Curitiba, v. 2, n. 4, p. 105-113, 1987.

MIRANDA, T. M.; AMOROZO, M. C. M. Influência de estímulos visuais na coleta de dados etnobotânicos através do método da listagem livre. In: ENCONTRO DE ETNOBIOLOGIA E ETNOECOLOGIA DA REGIÃO CENTRO-OESTE, 1.; WORKSHOP DE PLANTAS MEDICINAIS, 7., 2003, Doutorado, MS. Anais... Doutorado, 2003.

PANTOJA, I. Planejamento Privado social: Práticas da Vale em municípios do Maranhão. In: SEMINÁRIO POLÍTICA E PLANEJAMENTO, 2, 2010, Curitiba. Anais... Curitiba: Ambiens, 2010. [CD].

ROMANI, C. Comunidades caiçaras e a expansão portuária em Santos: uma análise histórica do conflito. Revista Científica Integrada, Ribeirão Preto, ano 1, v. 1, p. 1-12, 2010.

SANT'ANA-JUNIOR, H.A. Conflitos socioambientais no Maranhão e sua relação com grandes projetos de desenvolvimento. In: JORNADA INTERNACIONAL DE POLÍTICAS PÚBLICAS, 4., 2009, São Luís. Anais... São Luís: PPGPP/UFMA, 2009. p. 1-8.

SAS INSTITUTE. JMP Statistics and Grafics Guide, Version 3.2.6. (computer software and manual). Cary, NC, 1995.

SILVA JÚNIOR, M. G. et al. Caracterização da ictiofauna de três canais de maré do estuário do rio paciência, ilha de São Luís, estado do Maranhão. Arquivos de Ciências do Mar, Fortaleza, v.46, p. 5-21, 2013.

SOUSA. D. B. P.; ALMEIDA, Z. S.; CARVALHO-NETA, R. N. F. Biomarcadores histológicos em duas espécies de bagres estuarinos da Costa Maranhense, Brasil. Arquivo Brasileiro de Medicina Veterinária e Zootecnia, Belo Horizonte, v. 65, n. 2, p. 369-376, abr. 2013. 
STRIDE, R. K. Diagnóstico da pesca Artesanal Marinha do Estado do Maranhão. São Luís: CORSUP/EDUFMA, 1992. v. 2.

UNIVERSIDADE FEDERAL DO MARANHÃO. Fundação Sousândrade; UNIVERSIDADE ESTADUAL DO MARANHÃO. Departamento de Oceanografia e Limnologia. . Zoneamento costeiro do Estado do Maranhão. São Luís, 2003. 2 CD-ROM.

VALE. Departamento de Meio Ambiente e Desenvolvimento Sustentável. Relatório de Sustentabilidade 2008. Rio de Janeiro, 2008. Disponível em:<www.vale.com>. Acesso em 03 nov. 2013.

. Relatório de Sustentabilidade 2009. Rio de Janeiro, 2009. Disponível em:<www.vale.com>. Acesso em 03 nov. 2013.

Relatório de Sustentabilidade 2010. Rio de Janeiro, 2010. Disponível em:<www.vale.com>. Acesso em 03 nov. 2013. ; UNIVERSIDADE FEDERAL DO MARANHAO.

Laboratório de Hidrologia. Quarta Campanha do Programa de Monitoramento da biota aquática e avifauna, qualidade de águas costeiras e sedimento marinho - Píer IV. São Luís, 2012. Relatório Técnico.

VIERTLER, R. B. Métodos antropológicos como ferramenta para estudos em etnobiologia. In: AMAROZO, M. C.; MING, L. C.; SILVA, S. M. P. (Eds). Métodos de coleta e análise de dados em etnobiologia, etnoecologia e disciplinas correlatas. Rio Claro: Ed. Unesp, 2002. p.11-30.

\section{NOTAS:}

1 Depoimento retirado da entrevista realizada na pesquisa.

2 Depoimento retirado da entrevista realizada na pesquisa.

3 MA: Impasse entre pescadores e Vale por causa de indenização (Disponível em: $<$ http:// forumcarajas.org.br/>).

4 Pescadores do Boqueirão rejeitam proposta de indenização da Vale (Disponível em: $<$ http:// danielsmotta.blogspot.com.br/2009/10/pescadores-do-boqueirao-rejeitam>).

5 Depoimento retirado da entrevista realizada na pesquisa.

6 Depoimento retirado da entrevista realizada na pesquisa.

7 Depoimento retirado da entrevista realizada na pesquisa.

8 Depoimento retirado da entrevista realizada na pesquisa. 